\title{
Broadband Internet: \\ Net Neutrality versus Open Access
}

\author{
Christiaan Hogendorn*
}

May 7, 2007

\begin{abstract}
"Network neutrality" and "open access" are two policies designed to preserve openness on the Internet. Open access mandates openness of conduits (e.g. television cable and DSL) to intermediaries (e.g. America Online), while network neutrality mandates openness to advanced content (streaming video, interactive e-commerce, etc.). We develop a systems model with free entry and competition in all three industry segments (conduits, intermediaries, and content) and examine the effects of the two types of regulation. We find that open access does not necessarily result in more openness of content and is not a substitute for network neutrality.
\end{abstract}

JEL classification: L1, L5, L9

Keywords: network neutrality, open access, broadband

${ }^{*}$ Economics Department, Wesleyan University, 238 Church Street, Middletown, CT 06457; e-mail: chogendorn@wesleyan.edu. I thank the editor, an anonymous referee, Gerald Faulhaber, Elizabeth Bailey, Paul Kleindorfer, Richard McLean, Gil Skillman, Yossi Spiegel, Joel Waldfogel, Dennis Yao, and participants of the 2006 INFRADAY conference. Madalina Ursu provided able research assistance. 


\section{Introduction}

May the owners of communications infrastructure choose who accesses that infrastructure? Frequently this question is cast in terms of content and conduit. Owners of cable television conduits do choose which channels to carry. Owners of telephone conduits are common carriers and may not discriminate among callers who produce telephone "content." That much is clear, but the picture is clouded when intermediary firms are added between the conduit and content. That is the situation today with regard to Internet access, and in this paper we provide a framework for thinking rigorously about openness with intermediaries.

The Telecommunications Act of 1996 introduced resellers between the local telephone conduit and the caller/consumer. Then broadband Internet put telephone and cable companies into competition for the first time. By law, telephone companies had to open their conduits to intermediaries, first to dial-up Internet Service Providers (ISPs), and then to broadband Competitive Local Exchange Carriers (CLECs). Cable companies had no such regulation, and they successfully fought off "open access" requirements at the local and national level. But mergers in the cable industry led to a series of consent decrees that did provide for intermediaries between cable companies and consumers. Opinion then turned against these open access requirements, which have been blamed for the slow deployment of advanced telecoms services in the United States (Hausman 2002). ${ }^{1}$ More recently, there has been concern that open access is not enough, and network neutrality has been proposed as an alternative, stronger policy (Wu 2003).

Part of the cause of this controversy is that two regulatory traditions are clashing (Hogendorn 2005). More important, technological change has created new types of intermediaries, including Internet Ser-

\footnotetext{
${ }^{1}$ Strong arguments for and against open access respectively are Lemley and Lessig (2001) and Hazlett and Bittlingmayer (2003).
} 
vice Providers, portals, virtual conduit operators, and content aggregators. Like telephone resellers, intermediaries are the middlemen between the conduit and the content, but unlike in telephone, they are not common carriers with regard to content. This means that openness of the conduit to service providers (what is meant by "open access") is not equivalent to openness to content (what we argue is or should be meant by "net neutrality").

No clear principle has been developed as to which type of openness is more desirable. Telephone common carrier regulation favored openness to content, but that rule was laid down long before there was a distinction between telephone company and intermediary. The first Internet intermediaries were the dial-up ISPs. These were initially a perfectly competitive industry of small firms, and they behaved like common carriers even without regulation (Greenstein forthcoming). Indeed, the technology of the Internet made it difficult for early ISPs to control web page content in any way. Now intermediaries are much larger, more technologically diverse, and less competitive. They have more incentive and ability to control content.

This paper provides a framework for analyzing policies toward openness. The central decision in the model concerns an intermediary that sells subscriptions to consumers and also sells access to content providers. This means the intermediary is a two-sided network (Rochet and Tirole 2006) that must determine a "price structure," i.e. whether to favor the consumer or the content side of the market. Here we focus on the content side, where the intermediary has conflicting incentives: to offer a large amount of content in order to attract subscribers or to limit content competition in order to create rents which it can expropriate.

Our model addresses the same general question as Gehrig (1998), namely whether the owner of a marketplace gains or loses from hosting more firms. In his paper, when there is sufficient differentiation between markets, there is an interior equilibrium in which market owners 
will balance the conflicting incentives of variety for consumers versus rent extraction from producers. This result echoes the systems model of Church and Gandal (1992) who also find interior equilibria when software firms choose which of two incompatible computer platforms to develop for. Although we use different mathematical techniques, we also find a similar interior equilibrium.

Rubinfeld and Singer (2001) consider vertical integration and vertical restrictions in broadband, but the setting and results are not the same. They examine the incentives of broadband conduits to treat their own vertically integrated content preferentially or to foreclose it to other conduits. They argue that a firm like Time Warner might have an incentive to exclude content on its America Online service that competes with content produced by Time Warner. Church and Gandal (2000) show a similar result in a hardware-software system. van Schewick (2007) verifies that even non-monopolist intermediaries have incentives to discriminate; this is a key underpinning of our model. Chipty (2001) empirically finds that vertical integration does cause foreclosure in cable television. The results of these papers have parallels in our model, but in our case "vertical integration" occurs between two downstream segments, the service provider and the conduit. Content, in our model, is always independent, and restrictions come through higher prices.

Our paper offers three contributions. First, it includes three industry segments - conduits, intermediaries, and content providers - and allows for free entry in each segment; previous papers generally consider only two conduits or intermediaries. Second, we do not assume that intermediaries are open to all content; instead they choose how much content to offer endogenously. Third, we examine the effect of open access and network neutrality regulation on this choice.

Our results are as follows. The principal difference between closed and open access is whether the intermediary provides several tied (closed) services to the consumer (Internet connectivity, local access infrastruc- 
ture, and other services like cable television or telephone) or simply one (open) service, namely Internet connectivity. ${ }^{2}$ Open access clearly allows more entry of intermediaries, since they have unrestricted access to conduits. But these stand-alone intermediaries receive less revenue from subscribers since they sell them only one product, which means they have more incentive to favor content restrictions in their profit maximization tradeoff. This means that open access does not necessarily increase the content available to consumers.

Network neutrality, on the other hand, works at the content end of the supply chain. It removes the possibility of intermediaries restricting content, regardless of whether the intermediaries are vertically integrated with conduits. Thus, network neutrality could reduce the profits of intermediaries and reduce the number that enter the market, but it would not allow the content restrictions that could stem from open access.

There is some empirical evidence supporting our results in the related premium TV market. In this market we can think of cable TV companies as integrated conduits/intermediaries and channels as content. Savage and Wirth (2005) find that potential entry of additional cable television carriers causes incumbent carriers to offer more channels. And Anderson, Fjell, and Foros (2004) show that interactive TV and regular broadband are not substitutes, suggesting that premium content reductions can succeed even when there is access to conventional Internet. However, this evidence does not speak to the three-level relationships that exist under open access.

In the next section we discuss the concepts of open access and net neutrality. In Section 3 we present a model of competition with open access, i.e. any mixture of conduits and intermediaries where intermediaries decide how much content to offer. In Section 4 we compare open

\footnotetext{
${ }^{2}$ Hazlett and Bittlingmayer (2003) discuss multi-service offerings of cable television companies.
} 
access with closed access and with network neutrality. We present extensions to the model and conclusions in section 5 .

\section{Openness and Neutrality}

\subsection{Conduits, Intermediaries, and Content}

Communications networks consist of numerous layers. For example, the cable television supply chain consists of initial inputs produced by studios, aggregation by program services (channels), and distribution by cable operators (Chipty 2001). The supply chain for broadband Internet is even more complex, consisting of a large number of platforms (Greenstein 2000). Most of the platforms are competitive markets, but Greenstein notes that continued competition is not assured. For purposes of analysis, we consider three layers: conduits, intermediaries, and content firms. ${ }^{3}$

Content Firms. The meaning of "content" has expanded relative to traditional media like television. While movies and TV-type programming are among the categories of broadband Internet content, online retail stores, mapping services, instant messaging, and so forth also provide content. ${ }^{4}$ Probably the most contentious form of content from a current policy perspective is voice over IP (VoIP) telephony. Already there has been at least one case of a service provider blocking a VoIP content provider. ${ }^{5}$

\footnotetext{
${ }^{3}$ Wireless data has a similar structure. We think it is likely that calls for open access and/or network neutrality will develop in wireless, and we believe our model translates directly to that setting.

${ }^{4}$ Communications networks also allow users to communicate with one another and host their own personal content. Coffman and Odlyzko (2002) argue that two-way peer-to-peer communications are the most important Internet service, which would make other regulatory issues subordinate. But even these peer-to-peer activities are usually facilitated by upstream firms (e.g. MySpace or YouTube).

${ }^{5}$ Mark Sullivan, "Vonage Hits ISP Resistance," Light Reading March 30, 2005.
} 
Intermediaries. The intermediary sector has been the fastest changing in recent years. The pioneers in this field were the dial-up Internet Service Providers that provided a simple, leased connection to the Internet backbone. ISPs had no editing capability and behaved like common carriers, but this was a market outcome rather than a regulatory one. Greenstein (forthcoming) describes how some intermediaries, particularly America Online (AOL) and Microsoft Network (MSN), had more extensive proprietary offerings. NRC (2002) discusses discrimination in favor of certain content and a "walled garden" approach in which access to the general Internet is difficult or even unavailable. They note that just because a garden is walled does not mean it is small, so it is not clear that consumers would be made worse off. In our approach, consumers perceive content firms that pay access fees as markedly better; we do not require that the general Internet be outright disconnected.

More recently, the role of intermediary has become blurred as many new firms have gained power at levels above the Internet packet layer. While routing packets and providing basic connectivity functions are still important, most users' Internet experiences are now more heavily influenced by search and portal intermediaries. Indeed, Google, Yahoo, and MSN dominate the search industry, with market shares of $49 \%$, $22 \%$, and $11 \%$ respectively (Nielsen Netratings, April 24, 2006).

In many cases, conduit owners have created strategic alliances with leading intermediaries. For example, Yahoo has partnerships with both Verizon and AT\&T to offer a co-branded Internet portal service to broadband customers. Verizon's deal with Yahoo was a blow to Microsoft's MSN, which previously had a similar arrangement. While these alliances are not quite "closed access" - they do not preclude access to competing intermediaries using conventional web browser technology they do give preferential treatment to certain intermediaries. For example, the Yahoo service is integrated in the broadband providers' installation software, and subscribers receive some extra benefits such as 
expanded e-mail storage space on Yahoo. ${ }^{6}$

Conduits. The final link (lowest level) in the supply chain is the conduit: the cable, DSL, or wireless connection to the subscriber's home. This level involves large fixed and sunk costs. In that sense it is quite similar to other types of infrastructure like electricity or piped water. However, its economies of scale are not so large as these, so some competition may be possible, even in the long run. For now, there is widespread competition between DSL and cable in the US. Faulhaber and Hogendorn (2000) found that multiple wired conduits could coexist in longrun equilibrium in most urban and suburban areas, provided that there were no regulatory barriers. Wireless competitors may also arise. Still, the number of conduits is small, so market power is an issue.

Use of the Internet. To fix ideas, it will be helpful to consider how conduits, intermediaries, and content firms interact in typical Internet use. Figure 1 shows a stylized description of the connections involved. A household uses conduit $C$ to reach an Internet router (generally owned either by the conduit or an independent Internet service provider). From there, traffic can proceed directly to any content firm over link 1 . Or it can proceed to a search engine, portal, or other intermediary over link 2. And depending on what this intermediary does, traffic may continue between the intermediary and the final content over link 3 .

\section{INSERT FIGURE 1 HERE.}

Let us give a simple example of how these links come into play. Suppose an Internet user wants to view a video clip from the CBS TV Show "60 Minutes." She could do so by one of the following three methods:

\footnotetext{
${ }^{6}$ Almar Latour and Kevin Delaney, "Yahoo and Verizon Plan to Offer Co-Branded Web-Portal Service," The Wall Street Journal, January 18, 2005, pg. B4.
} 
1. If the user already knows that 60 Minutes is a CBS program, she could type "www.cbs.com" into her web browser and navigate to the 60 Minutes webpage. This activity uses link $C$ for local connectivity and link 1 over the Internet.

2. Alternatively, the user may not be sure of 60 Minutes' address, in which case she might run a search on "60 Minutes" using Yahoo. In that case, she uses link $C$ for local connectivity and link 2 to reach Yahoo. Yahoo provides information on 60 Minutes' web address, which is sent back over link 2 . Then the user uses link 1 to communicate directly with the CBS website.

3. A more complex case occurs if the user uses link 2 and finds 60 Minutes content directly through Yahoo's "Video" page. At that point, the video is made available directly within a Yahoo-branded video player as part of a paid relationship with the television network. The CBS content is completed mediated by Yahoo through link 3.

There is a key transformation from case 2 to 3 . In case 2, Yahoo provides a service, but the only intermediary between the user and her chosen destination on the web is the ISP. But in case 3, Yahoo has become an intermediary. CBS and Yahoo have an alliance, and Yahoo was not in any way required to provide CBS the link from its main page, and indeed it does not provide similar links to competing TV content. This may seem like business as usual, but it essentially changes who is the most important intermediary.

Most of the early discussion of openness on the Internet focused on link $C$, and the question was whether more than one ISP could use the same conduit. More recently, there has been some refocusing of attention on link 2, as companies like Google and Yahoo have worried that they might face higher prices or degraded service in the absence of network neutrality. There has been almost no discussion of the openness of link 
3. Indeed, the lack of openness of link 3 seems to be taken for granted as an important component of Internet business models.

The purpose of this paper is not necessarily to argue that link 3 must be opened. But we do think it is vitally important to analyze the effect on link 3 of policies directed at links $C$ or 2 . Since link 3 is not open, there is nothing about those policies that necessarily leads to overall, end-to-end openness on the Internet, and this needs to be considered in the policy debate.

\subsection{US Conduit Regulation}

Because of this potential for market power in the conduit layer, mergers involving telephone or cable television firms have led to calls for regulation. The late 1990s mergers of AT\&T with TCI and MediaOne led Portland, Oregon and other cities to call for a choice of ISPs on these conduits rather than a single vertically integrated ISP (FCC 1999). AT\&T and its allies maintained that open access amounts to giving away their expensive infrastructure investment, while the cities and several ISPs argued from a common-carrier analogy. The arguments only concerned whether the conduit should offer open access to ISPs, not whether the ISP $(\mathrm{s})$ should offer open access to content firms. In March 2002, the FCC concluded that cable broadband is an "information service" and not subject to any open access requirements (FCC 2002). This ruling was challenged by California ISP Brand X Internet but was upheld by the Supreme Court in $2005 .^{7}$

Open access reappeared when the FTC took up the review of the AOL Time Warner merger. In its consent decree, the FTC forced AOL to allow other ISPs access to the Time Warner cable conduit before it

\footnotetext{
${ }^{7}$ Amy Schatz, Jesse Drucker and Dionne Searcey, "Small Internet Providers Can't Use Cable Lines; Is Wireless the Answer?" The Wall Street Journal, June 28, 2005, pg. B1.
} 
could offer its own service. ${ }^{8}$ However, this decree was much less strict than what telephone carriers were subject to under the Telecoms Act. ${ }^{9}$

In 2002, the FCC began an inquiry into removing open access requirements for telephone. In February 2003 this led to a celebrated rupture between Commissioners Powell and Martin over the proper way to relax open access rules on incumbent telephone companies. ${ }^{10}$ In August 2005, the FCC determined that the Brand X case mentioned above also gave it authority to remove requirements for telephone-based conduits to unbundle their services. ${ }^{11}$

Partly because of the relative defeat of open access in the United States, attention has shifted to an alternative policy labeled "network neutrality." "Net neutrality has no widely accepted precise definition, but usually means that broadband services charge consumers only once for Internet access, do not favor one content provider over another, and do not charge content providers for sending information over broadband lines to end users." (Hahn and Wallsten 2006, pg. 1)

Responding to proponents of network neutrality, the conduits have been quite aggressive. In November 2005, Edward Whitacre, CEO of AT\&T, was interviewed about large intermediaries like Google and said, "Now what they would like to do is use my pipes free, but I ain't going to let them do that, because we have spent this capital and we have to have a return on it. So there's going to have to be some mechanism for these people who use these pipes to pay for the portion they're using." ${ }^{12}$ An

\footnotetext{
${ }^{8}$ Ironically, AOL's inability to gain access to non-Time Warner cable systems was a major blow to the company. See "AOL Rethinks its Game Plan on Internet Access," Wall Street Journal, April 19, 2002, pg. A3.

${ }^{9}$ Julia Angwin, “'Open Access' Isn't So Open at Time Warner," Wall Street Journal, May 6, 2002, pg. B1 describes how "Cable companies can hand pick a few competitors that agree to their stringent terms."

${ }^{10}$ A nice description with an amusing title is "The FCC Presses Auto-Destruct," The Economist, February 27, 2003.

11 "FCC Zaps Broadband Carriage Regs," Light Reading, August 5, 2005.

12 "At SBC, It's All About 'Scale and Scope," Business Week, November 7, 2005.
} 
interesting rejoinder to this comment comes from Andrew Odlyzko of the University of Minnsota, who says "What makes them think that they are going to charge Google, as opposed to Google charging them?"13

In 2005, two regional ISPs temporarily blocked Vonage's VoIP service, and there was speculation that this was done to favor their own vertically integrated VoIP service. In one case, the FCC ordered the ISP to reinstate Vonage service and pay a fine. ${ }^{14}$ In 2006, there was a proposal for direct price controls on broadband service to prevent a two-tiered pricing scheme with priority service. Although that regulation was not passed by Congress, the bill did contain provisions that would allow the FCC to prevent ISPs from blocking websites. ${ }^{15}$

\subsection{European Conduit Regulation}

What is happening in the US is influencing the decision-making process of other parts of the world, including Europe. Recently there has been growing interest among European telecom firms in charging intermediaries like Google for content distribution. These charges might take the form of a higher charge for preferential treatment. This has led to European calls for network neutrality, although France Telecom is on the record saying that "France Telecom thinks the debate on 'network neutrality' is an American debate. In Europe, the regulatory and competitive environment is completely different - the US and European situations are not comparable." 16

In June 2006, the European Commission announced a new European telecom regulation framework, and in August it ordered Deutsche

\footnotetext{
13 "Changing the rules, How should regulators respond to convergence?" The Economist, October 14, 2006.

14 "Vonage Hits ISP Resistance," Light Reading, March 30, 2005.

${ }^{15}$ Jenny Johnson and Patti Waldmeir, "Telecoms Groups Win 'Net Neutrality' Battle in Congress," Financial Times, April 27, 2006.

${ }^{16}$ Richard Waters and Mark Odell, "A Two-Speed Internet? Why Network Operators are Flexing their Muscles," Financial Times, March 29, 2006, pg. 15.
} 
Telekom to open its network. Similarly, the British regulator Ofcom has ordered BT to open its next generation network. ${ }^{17}$ Thus, the concept of open access seems to be alive in Europe.

\section{The Model}

Our model focuses on competition among content firms, intermediaries, and conduits. We believe the interaction of all three is crucial to an understanding of the broadband policy debate. This is especially so because broadband content is a very innovative industry with potential to affect the overall economy while the intermediaries and conduits are more specialized.

\subsection{The Game}

There are $M$ online households which value content, connectivity, and other services. Any number of conduits may serve these households by building infrastructure. We consider three policy regimes:

1. Under closed access, each conduit operates one vertically integrated intermediary, and this intermediary chooses how much content to offer.

2. Under open access, each conduit must provide (implicitly at a nondiscriminatory price) access to intermediaries, but intermediaries can still choose the amount of content to offer.

3. Under full network neutrality, each conduit must provide (implicitly at a nondiscriminatory price) access to intermediaries and each intermediary allows all content on a nondiscriminatory basis. ${ }^{18}$

\footnotetext{
17 "Changing the rules, How should regulators respond to convergence?" The Economist, October 14, 2006

${ }^{18}$ While all proposals for network neutrality address access to intermediaries, many
} 
Open access is the most complex, so we build our model around it and then consider closed access and network neutrality as special cases. For the open access case, the firms compete in a three-stage game: (i) conduits and intermediaries enter the market; (ii) intermediaries negotiate alliances with content firms; (iii) consumers choose one conduit and one intermediary and purchase a variety of content through their chosen intermediary.

Stage 1: Entry. Let the number of conduits that enter be $N^{C}$ and the number of intermediaries be $N^{I}$. Respectively, their fixed costs of entry are $F^{C}$, the capital cost of the conduit, and $F^{I}$, the setup costs of the intermediary. We assume these costs are identical for each potential entrant.

Stage 2: Intermediaries Negotiate Alliances with Content Firms. Let there be a large pool of potential content firms, and those which enter become monopolistic competitors. We interpret this to mean that each content firm offers roughly the same type of content (e.g. multiple music servers) but with some horizontal product differentiation. Of course there are in fact many types of content, but our "representative type" approach is equivalent to having many different types, provided the cross-elasticities between types are low so they do not compete with one another.

Each intermediary $i$ chooses to negotiate an alliance with $n^{i}$ of these content firms. In exchange for hosting its product, a content firm pays an access fee equal to a share of its profits. The outcome of this bargaining is that content firms pay a share $\alpha\left(N^{I}\right)$ of their profits, where $\alpha_{N}<0^{19}$ to reflect a decrease in bargaining power when there are more intermediaries competing. The profit of a typical content firm on interdo not include the relationship of content to intermediaries. Thus, what we mean by "network neutrality" in this model is stronger than many policy proposals that have been discussed in the press.

${ }^{19}$ Subscripts denote derivatives. 
mediary $i$ is $\pi\left(n^{i}\right)$. The profile $\mathbf{n}=\left(n^{1}, \ldots, n^{N^{I}}\right)$ describes the number of content firms available on all $N^{I}$ intermediaries. To be clear, we are not suggesting that intermediaries will block existing, conventional websites. The content firms we have in mind are part of the higher-quality tier of service that network neutrality advocates have expressed concern over. $^{20}$

We assume any costs of hosting content are constant, and without loss of generality let them be zero. We also assume that there are no fixed costs of entry for content firms. This assumption allows us to focus on the number of content firms without concern for the identity of each firm. ${ }^{21}$

\section{Stage 3: Consumers Subscribe to Conduits and Intermedi-} aries and Consume Content. Each consumer single-homes by purchasing subscriptions to one and only one conduit and intermediary. We discuss the possibility of consumers multi-homing on more than one intermediary in the conclusion. Consumer utility from (any) one conduit is $t$, reflecting connectivity and other conduit services like cable TV and/or telephone service. Utility from an intermediary has two components: utility from access to content (more is better) and idiosyncratic utility for each intermediary based on marketing, technology, the user interface, etc.:

$$
u^{i}=v\left(n^{i}\right)+\epsilon^{i}
$$

We model consumer choice using multinomial logit demand, with $v\left(n^{i}\right)$ the systematic utility attributable to observable characteristics of the intermediary and $\epsilon^{i}$ the unsystematic utility with a type- 1 extreme value distribution. Intermediaries can obtain revenue from subscribers

\footnotetext{
${ }^{20}$ Forrester Research has predicted that more content will move to a closed network that will mirror the Internet, see "A New Tech Battle for the Home. The Wall Street Journal, January 3, 2005.

${ }^{21}$ Adding fixed costs is not a problem as long as $\alpha$ is low enough that content firms have sufficient operating profits to cover the fixed costs.
} 
through a combination of monthly subscription fees, service charges, and indirectly through advertising. Thus, the intermediaries capture a share $\beta\left(N^{I}\right)$ of $v\left(n^{i}\right)$. Likewise, conduits capture a share $\beta\left(N^{C}\right)$ of $t .^{22}$

Since consumers buy content only through their intermediary, content competition takes place separately on each intermediary. We model this competition using a reduced form of monopolistic competition. Spence (1976, pg. 410) argues that "The entry of an additional product has several effects. It increases the surplus from the new product, but lowers the demand for existing products and causes them to contract output. In terms of the surplus, there are gains and losses." This suggests that $\pi\left(n^{i}\right)$ is decreasing and that $v\left(n^{i}\right)$ is increasing and concave. The total surplus (per subscriber) from content production and consumption on intermediary $i$ is

$$
n^{i} \pi\left(n^{i}\right)+v\left(n^{i}\right)
$$

In most monopolistic competition models, the total surplus, gross of any fixed costs, is increasing in the number of firms, provided that consumers value variety enough (Mankiw and Whinston 1986). But what matters to the intermediary is the portion of total surplus it can appropriate to itself. Here that is:

$$
s\left(n^{i}, N^{I}\right)=\alpha\left(N^{I}\right) n^{i} \pi\left(n^{i}\right)+\beta\left(N^{I}\right) v\left(n^{i}\right)
$$

The behavior of this appropriable surplus function $s(\cdot, \cdot)$ is crucial to the outcome of the model. If $s$ is increasing in $n$, then even a monopoly intermediary would want to offer as much content as possible. If, on the

\footnotetext{
${ }^{22}$ It would be preferable to model the subscription price-setting subgame explicitly. However, analytical difficulties have always limited 2-stage quality-price games to the case of duopoly (see Shaked and Sutton (1982) for pure vertical differentiation, Ferreira and Thisse (1996) for Hotelling horizontal differentiation with quality choice, and Rhee (1996) for the multinomial logit with quality choice). Using a duopoly model to study broadband would assume away a main policy goal, namely entry of additional conduits and intermediaries into the market.
} 
other hand, the following property holds, then an intermediary would choose an interior profit maximizing number of content firms:

\section{Decreasing Surplus Property (DSP):}

$$
s_{n n}\left(n^{i}, N^{I}\right) \leq 0 \text { and } \exists \hat{n} \geq 1 \text { s.t. } s_{n}\left(n^{i}, N^{I}\right)<0, \forall n^{i}>\hat{n}
$$

DSP is a statement about the intensity of competition between content providers. Given a fixed number of subscribers, total profits, $n \pi(n)$, decrease sufficiently in $n$ to overcome the increase in the appropriable share of consumer surplus from the increase in $n$. This is clearly not true if $\beta$, the share of consumer benefits appropriable by the intermediary, is large, but it is likely if $\beta$ is small.

Are we in fact in an environment where DSP holds? One reason to think so is empirical: Yahoo, MSN and the like do in fact sell special arrangements to content firms, and Google sells advertising to some of them at prices which presumably exceed marginal cost. A second reason is theoretical and is based on price discrimination. It is fairly easy to bargain with firms over profit-sharing in alliances, with each firm in effect paying a different price. Identifying different types of consumers and charging them different prices is likely to be much more difficult. This suggests that $\alpha\left(N^{I}\right)>\beta\left(N^{I}\right)$, perhaps much greater, and that therefore DSP is likely to hold. Evans (2003, pg. 337) provides a useful table showing that charges are lower to the consumer side of the market in many two-sided platform industries.

\subsection{Equilibrium}

Stage 3. We solve the game backwards to find a subgame perfect Nash equilibrium. For now, let consumers choose a conduit and an intermediary in "mix-and-match" fashion - any intermediary can be used along with any conduit. We assume that consumers pay the conduit directly for its service, and intermediaries do not pay the conduit anything. All conduits offer the same services that give utility $t$, so they have equal 
market shares.

Consumers choose intermediaries according to the multinomial logit model. The strength of the unsystematic utility is parameterized by the variance of $\epsilon$, which we denote $\sigma$. The larger is $\sigma$, the stronger are the tastes of each consumer for his or her preferred intermediary, regardless of the number of content firms available on other intermediaries.

The outcome of the stage 3 subscription decision is a market share function, which gives the probability that a consumer chooses intermediary $i$ given the profile of content firms available on all the intermediaries:

$$
\Phi^{i}(\mathbf{n})=\frac{\exp \left(\frac{\left(1-\beta\left(N^{I}\right)\right) v\left(n^{i}\right)}{\sigma}\right)}{\sum_{j=1}^{N^{I}} \exp \left(\frac{\left(1-\beta\left(N^{I}\right)\right) v\left(n^{j}\right)}{\sigma}\right)}
$$

The closed form of this market share function is one of the advantages of logit models. See Anderson, de Palma, and Thisse (1992) for detail on the derivation and application of the logit to theoretical oligopoly models. The intuition is that each firm's market share is proportional to the utility offered by that firm compared to the total utility offered by all firms. Market share $\Phi^{i}$ increases in the number of content firms on intermediary $i$ and decreases in the number of content firms on intermediaries other than $i$. Since the total number of consumers is $M$, the number of subscribers to intermediary $i$ is $\Phi^{i}(\mathbf{n}) M$.

Stage 2. In stage 2, the intermediaries noncooperatively choose the number of content firms. For any $n^{i}$, the intermediary receives $\alpha\left(N^{I}\right) \pi\left(n^{i}\right)$ per subscriber from each of the $n^{i}$ content firms. The total profit of intermediary $i$, including revenue from both content firms and subscribers, is

$$
s\left(n^{i}, N^{I}\right) \Phi^{i}(\mathbf{n}) M
$$

In equilibrium, all intermediaries simultaneously maximize (2), and we have the following result: 
Proposition 1: For sufficiently large $\sigma$, there is a symmetric Nash equilibrium in which all intermediaries host $n^{*}$ content firms and have equal market shares $\Phi^{i}\left(\mathbf{n}^{*}\right)=1 / N^{I}{ }^{23}$ If DSP does not hold, each conduit hosts every possible content firm, while if DSP holds, ${ }^{24}$ the profitmaximizing $n^{*}$ is an interior solution to

$$
s_{n}\left(n^{*}, N^{I}\right) \Phi^{i}\left(\mathbf{n}^{*}\right)+s\left(n^{*}, N^{I}\right) \frac{d \Phi^{i}\left(\mathbf{n}^{*}\right)}{d n^{i}}=0
$$

Proof: We begin by determining which values of $n^{i}$ are candidates for equilibrium. We then prove that the profit function is everywhere concave for these values.

The derivative of (1) is

$$
\frac{d \Phi^{i}(\mathbf{n})}{d n^{i}}=\left(1-\beta\left(N^{I}\right)\right) v_{n} \frac{\Phi^{i}\left(1-\Phi^{i}\right)}{\sigma}
$$

Thus, the first order condition (3) can be written

$$
s_{n} \Phi^{i}+s\left(1-\beta\left(N^{I}\right)\right) v_{n} \frac{\Phi^{i}\left(1-\Phi^{i}\right)}{\sigma}=0
$$

The first term of (4) is negative by DSP; the second term is always positive. The second order condition is

$$
\begin{aligned}
& s_{n n} \Phi^{i}+2 s_{n}\left(1-\beta\left(N^{I}\right)\right) v_{n} \frac{\Phi^{i}\left(1-\Phi^{i}\right)}{\sigma}+ \\
& s\left(1-\beta\left(N^{I}\right)\right) v_{n n} \frac{\Phi^{i}\left(1-\Phi^{i}\right)}{\sigma}+ \\
& s\left(1-\beta\left(N^{I}\right)\right)^{2}\left(v_{n}\right)^{2} \frac{\left(1-\Phi^{i}\right)\left(1-2 \Phi^{i}\right)}{\sigma^{2}}<0
\end{aligned}
$$

The first and second terms are negative by DSP. The third term is negative for concave $v$. The fourth term is nonpositive for the case of $\Phi^{i} \geq \frac{1}{2}$. For the case of $\Phi^{i}<\frac{1}{2}$, we note that if the sum of the third and

\footnotetext{
${ }^{23}$ For low $\sigma$, there may be a vertically differentiated, asymmetric equilibrium as in Shaked and Sutton (1982), but this can only be found numerically.

${ }^{24}$ Actually DSP is sufficient but not necessary; as long as $s$ is decreasing in $n$ and not too convex, the interior equilibrium exists.
} 
fourth terms is negative, the entire second derivative is negative. Thus a sufficient condition for the SOC to hold is

$$
s\left(1-\beta\left(N^{I}\right)\right) \frac{1-\Phi^{i}}{\sigma}\left[v_{n n} \Phi^{i}+\left(1-\beta\left(N^{I}\right)\right)\left(v_{n}\right)^{2} \frac{1-2 \Phi^{i}}{\sigma}\right]<0
$$

The first terms of (5) are positive, so the inequality holds if the bracketed term is negative. Rearranging that term gives

$$
\frac{1}{\sigma}+\left(\frac{v_{n n}}{(1-\beta(K))\left(v_{n}\right)^{2}}-\frac{2}{\sigma}\right) \Phi^{i} \leq 0
$$

If $\sigma$ is sufficiently large, then (6) holds because the positive first term approaches 0 .

The first term in (3) is the profit effect. It indicates that a portion of the surplus in the content market becomes profit to the intermediary. Under DSP, the intermediary cannot capture as much of this surplus when it hosts more content firms. Working against this effect, the second term in (3) is the demand effect. It shows that hosting more content firms increases the market share of an intermediary. But the demand effect diminishes in $n$, so under DSP there may be an interior optimum number of content firms. To guarantee that the optimum is interior, it is important that the market cannot be tipped to one dominant intermediary. Church and Gandal (1992) showed that this requires strong enough heterogeneity in consumer preferences for the intermediary itself, as opposed to its quality level, and in our model the consumer preference parameter is $\sigma$. Thus, we need sufficiently large $\sigma$ to prevent market tipping.

Denote the stage 2 equilibrium total surplus that solves (3) by $S\left(N^{I}\right)=s\left(n^{*}, N^{I}\right)$. The effect of changes in $N^{I}$ on total surplus is Lemma 1: $\quad \frac{\partial n^{*}}{\partial N^{I}}>0 \quad S_{N}<0$ 
Proof: From (4), $n^{*}$ is the solution to

$$
s_{n}+s\left(1-\beta\left(N^{I}\right)\right) v_{n} \frac{1-\Phi^{i}}{\sigma}=0
$$

The derivative of (7) with respect to $N^{I}$ is:

$$
\begin{aligned}
& s_{n}+s_{n n} \frac{d n}{d N^{I}}+s(1-\beta) \frac{v_{n}}{\sigma}\left(-\frac{d \Phi}{d N^{I}}\right) \\
& +s\left(-\beta_{N}\right) \frac{v_{n}}{\sigma}(1-\Phi)+s(1-\beta) v_{n n} \frac{d n}{d N^{I}} \frac{1-\Phi}{\sigma} \\
& +s_{n} \frac{d n}{d K}(1-\beta) v_{n} \frac{1-\Phi}{\sigma}=0
\end{aligned}
$$

Solving for $d n / d N^{I}$ gives

$$
\frac{d n}{d N^{I}}=\frac{-s_{n}+s v_{n} \sigma^{-1}\left((1-\beta) \frac{d \Phi}{d N^{I}}+\beta_{N}(1-\Phi)\right)}{s_{n n}+(1-\beta) \sigma^{-1}(1-\Phi)\left(s v_{n n}+s_{n} v_{n}\right)}
$$

All terms in both the numerator and denominator are negative, so we have shown that $\frac{d n}{d N^{I}}>0$. It then follows immediately that $S_{N}=$ $s_{n} \frac{d n}{d N^{I}}<0$.

Lemma 1 says that when intermediary competition increases $\left(N^{I}\right.$ rises), each intermediary will host more content. There are two reasons. First, when an intermediary's market share falls, content firms on that intermediary make smaller profits, lowering the profit effect. Second, the intermediaries lose negotiating power and consumers retain more of their surplus, which strengthens the demand effect. For both reasons, intermediary competition increases the number of content firms hosted on each intermediary. In turn this reduces the intermediary's surplus.

Stage 1. Assuming that the intermediaries are sufficiently differentiated to achieve a symmetric equilibrium, they enter the market until

$$
S\left(N^{I}\right) \frac{M}{N^{I}}=F^{I}
$$

There must be a solution to (9) under DSP.

Conduits are symmetric by assumption, so they also have a symmetric free-entry condition:

$$
\beta\left(N^{C}\right) t \frac{M}{N^{C}}=F^{C}
$$




\section{Comparison of the Policies}

Thus far, the model describes open access with mix-and-match competition of conduits and intermediaries. Since the intermediaries can and do determine the amount of content, they reach an interior equilibirum with $n^{*}$ content firms available. In this section we alter the model to analyze the less open regime of closed access and the more open regime of full network neutrality.

\subsection{Closed Access}

Under closed access, there is no longer any requirement that every intermediary be accessible using every conduit. Referring to free-entry condition (9), we know that intermediary profits are decreasing in the number of intermediaries. Thus, conduits can in general increase total profits by foreclosing access to all but one intermediary. (With enough consumer preference for variety in intermediaries, two or more intermediaries could be optimal, but we will not examine this case). Thus, we will model closed access as a regime in which each conduit vertically integrates with one intermediary, forcing $N^{I}=N^{C} \cdot{ }^{25}$ From the point of view of our model, the separate consumer choice of a conduit disappears, and the intermediary problem from the last section is solved again, but with different parameters. Specifically, the fixed cost of an integrated intermediary/conduit is $F^{C}+F^{I}$, and the appropriable surplus function now includes the constant $t$ :

$$
s\left(n^{i}, N^{I}\right)=\alpha\left(N^{I}\right) n^{i} \pi\left(n^{i}\right)+\beta\left(N^{I}\right)\left(v\left(n^{i}\right)+t\right)
$$

First, note that the number of conduits may increase under closed access because an additional source of profit has been added to the

\footnotetext{
${ }^{25}$ Vertical integration is optimal in our model because the equilibrium of Proposition 1 involves market power, and integration essentially removes doublemarginalization in the number of content firms.
} 
conduits' profit functions. This is the main justification telephone and cable firms have used when lobbying for closed access, saying that they need the extra revenue to pay for capital investment in new conduits.

We now consider the effect of closed access on content and intermediaries. First, we look at the change in content holding the number of intermediaries constant. Next, we look at the change in the number of intermediaries, and last we look at the overall effect on content including the possibility of a change in the number of intermediaries.

There is more incentive for a vertically integrated conduit/intermediary to host content because it sells more services $(d v=t)$ to customers and thus customer market share is worth more. One way to interpret this is that under open access, there is a type of double-marginalization, and it is removed under closed access. The increase in content works to decrease $S$ while the additional service offerings work to increase it. The net effect on surplus can go in either direction, but we can bound it from above because a one unit change in $v$ always causes no more than a $\beta$ unit change in surplus through subscriber revenue.

Lemma 2: Changing from open to closed access increases the content per intermediary and increases surplus by less than $\beta$, holding the number of intermediaries constant:

$$
\frac{\partial n^{*}}{\partial v}>0 \quad S_{v}<\beta
$$

Proof: The derivative of (7) with respect to $v$ is:

$$
\begin{aligned}
& s_{n n} \frac{d n}{d v}+s(1-\beta) \frac{v_{n}}{\sigma}\left(-\frac{d \Phi}{d v}\right)+\left(s(1-\beta) v_{n n} \frac{d n}{d v} \frac{1-\Phi}{\sigma}\right) \\
& +\left(s_{n} \frac{d n}{d v}(1-\beta) v_{n} \frac{1-\Phi}{\sigma}\right)+\left((1-\beta) v_{n} \frac{1-\Phi}{\sigma}\right)
\end{aligned}
$$

There is no change in $\Phi$ when $v$ changes (unless $v$ changes so much that the equilibrium number of firms changes), so the second term drops out. Solving for $d n / d v$ gives

$$
\frac{d n}{d v}=\frac{-v_{n}}{\frac{s_{n n} \sigma}{(1-\beta)(1-\Phi)}+s v_{n n}+s_{n} v_{n}}
$$


All terms in the numerator and denominator are negative, so $\frac{d n}{d v}>0$.

$S_{v}=s_{n} \frac{d n}{d v}+\beta$ and $s_{n}$ is negative, so $S_{v}$ is bounded above by $\beta$.

Now consider the effect on the number of intermediaries. There are two important differences in the competitive situation of open access intermediaries versus integrated conduit/intermediaries: (i) stand-alone intermediaries do not have to build physical infrastructure, so their fixed cost of entry is lower (possibly much lower) and (ii) stand-alone intermediaries do not offer the non-content related services that give consumers utility $t$.

These conflicting effects make the comparison of closed to open access ambiguous. Totally differentiating (9) and noting that $v$ increases by $t$ and that the change in fixed cost is $F^{C}$, we find that the change in the number of intermediaries is:

$$
d N^{I}=\frac{M S_{v} t-N^{I} F^{C}}{F^{I}-S_{N} M}
$$

The denominator is positive because $S_{N}$ is negative by DSP, so equation (11) indicates that the free entry number of intermediaries responds negatively to the increase in fixed cost and positively to the increase in service offerings $t$.

We can put this comparison in terms of easily measured changes according to the following proposition:

Proposition 3: The number of intermediaries falls under closed access if and only if the percentage increase in fixed costs is greater than some fraction of the percentage change in surplus due to increased service offerings:

$$
\operatorname{sign}\left[d N^{I}\right]=\operatorname{sign}\left[S_{v}\left|\frac{t}{S}\right|-\frac{F^{C}}{F^{I}}\right]
$$

Proof: We saw in (11) that

$$
\operatorname{sign}\left[d N^{I}\right]=\operatorname{sign}\left[M S_{v} t-N^{I} F^{C}\right]
$$


In free-entry equilibrium, (9) requires that $S\left(N^{I}\right)=\frac{N^{I} F^{I}}{M}$, so multiplying the first term on the right hand side by $\frac{S}{S}$ gives

$$
\operatorname{sign}\left[d N^{I}\right]=\operatorname{sign}\left[\frac{N^{I} F^{I}}{M S\left(N^{I}\right)} M S_{v} t-N^{I} F^{C}\right]
$$

Now cancel terms and multiply the entire right-hand side by $\frac{1}{N^{I} F^{I}}$ :

$$
\operatorname{sign}\left[d N^{I}\right]=\operatorname{sign}\left[\frac{S_{v} t}{S}-\frac{F^{C}}{F^{I}}\right]
$$

Applying absolute value notation gives the desired result.

The intuition for Proposition 3 is that the increased fixed costs of having to own a conduit decrease the number of intermediaries, but this can be at least partially offset by the revenue that a conduit earns from offering other services. As we discuss below, one cannot rule out that actually $d N^{I}>0$ by appealing to "reasonable" values of the relevant changes.

We know from Lemma 2 that content will increase under closed access if the number of intermediaries is unchanged, so the question now becomes how large the reduction in intermediaries is.

Proposition 4: The number of content firms on a typical intermediary will fall under closed access only if closed access causes a sufficient reduction in the number of intermediaries:

$$
\exists \delta \leq-1 \quad \text { s.t. } \quad d n<0 \quad \text { iff } \quad d N^{I} \leq \delta
$$

Proof: Content decreases under closed access if the intermediaries' retained surplus increases :

$$
d n<0 \quad \text { iff } \quad\left(S_{v}-\beta\right) \frac{t}{S}+\frac{S_{N}}{S} d N^{I}>0
$$

From Lemma 2, the first term in (12) is negative. The fraction in the second term is also negative, so the inequality will only hold if $d N^{I}$ is sufficiently negative. 
The intuition here is that closed access must sufficiently reduce the number of intermediaries to counteract its direct, content-increasing effect in Lemma 2. Thus, we conclude that closed access can only reduce content if it results in a reduction in intermediaries.

\subsection{Network Neutrality}

The results about closed access may seem surprising, since much of the network neutrality debate suggests that it is precisely this kind of closure that would reduce freedom on the Internet. But the reason for these results is that open versus closed access only affects the conduitintermediary relationship. It leaves the intermediary-content relationship unregulated. Because of this, there are some restrictions on content in either regime, as long as the number of intermediaries is not too large.

Suppose that full network neutrality regulation required each intermediary to host every content firm that wanted access. In practice, this would mean that the price for hosting could not exceed some small markup over marginal cost. In that case, the intermediaries could no longer appropriate any surplus from the content firms, and the content firms would no longer earn any super-normal profits. The only remaining surplus available to intermediaries would come from consumers:

$$
s\left(n^{i}, N^{I}\right)=\beta\left(N^{I}\right) v\left(n^{i}\right)
$$

We already assumed that $v(\cdot)$ is increasing and concave; it will be simplest now to further assume that

$$
\lim _{n \rightarrow \infty} v(n)=\bar{v}
$$

Then there is no longer any stage 2 equilibrium, since content cannot be restricted, and the intermedaries' stage 1 free-entry equilibrium is

$$
\beta\left(N^{I}\right) \bar{v} \frac{M}{N^{I}}=F^{I}
$$


Clearly the amount of content on each intermediary must be greater than under open access. And also it is clear that the number of intermediaries must be weakly less, since they earn lower profits.

\subsection{Comparison}

Our results depend crucially on two parameters: $F^{I}$, the fixed cost of an intermediary, and $t$, the value of services provided by the conduit other than access to the intermediary. In this section, we consider the relative values of these parameters.

Low $\mathbf{F}^{\mathrm{I}}$, High t: The Classic Internet. When the Internet industry consisted of dial-up access to ISP intermediaries, the fixed cost of an intermediary was very low, and enormously lower than the cost of building out a conduit to residential homes. That means that $F^{C} / F^{I}$ was very large, and this suggests that closed access would drastically reduce the number of intermediaries. In fact, we can say fairly definitively, based on the actual outcomes of the dial-up world, that closed access would result in one or two intermediaries and open access would result in ten or more for most households.

If we consider the effect on content, we first note that in the dial-up world, $t$ was very large relative to $S$ because the Internet was in its infancy and thus much less valuable than services like telephone and cable television. This would temper the incentive for an intermediary to restrict content, which may help explain why content exclusion was quite rare even in countries that did have monopoly or duopoly intermediaries. The high value of $t$ also suggests that open access might not increase content greatly, but it seems likely that the very high number of intermediaries would overwhelm any such effect.

Comparing the three policies, we can then make three findings for the low- $F^{I}$, high- $t$ case: (i) Even closed access would result in fairly unrestricted content because of the high value of signing up consumers 
for other services. (ii) Open access would result in a large number of intermediaries entering the market, due to their low fixed costs, and the large amount of intermediary competition would promote largely unrestricted content. (iii) Network neutrality by definition creates unrestricted content, but since open access also creates unrestricted content in this setting, there would be no appreciable difference from or need for network neutrality.

Because the Internet began to develop in the dial-up case, it seems that policy even today is often based on that world. It was a world where open access and network neutrality were essentially synonyms, and a world where these types of openness were fairly unambiguously positive since the only alternative was telephone company monopoly control of the Internet intermediary function.

High $\mathbf{F}^{\mathrm{I}}$, Low t: Today's Internet. Today's intermediaries are very different from the Mom and Pop ISPs of the early 1990s. Indeed, as we have noted, the ISP role has become relatively unimportant and access has become increasingly closed with respect to ISPs. The intermediaries that are important today are the search and portal providers, and this industry is dominated by just three players, Google, Yahoo, and Microsoft. Clearly the fixed costs of one of these firms are very high. In fact, as wireless broadband becomes an option, it is not impossible that the fixed costs of a leading intermediary will surpass those of a conduit. Also, more and more services, such as telephone and video, seem to be moving to the intermediaries (for example, Google buys YouTube for video) so $t$ may be falling.

The comparison of the three policies in this setting is different from before. We can say that (i) Closed access probably results in the least content availability since it reduces the number of intermediaries. (ii) Open access may not increase the number of intermediaries very much since there are high fixed costs for these firms. (Indeed, if we think of the three companies mentioned above as the major intermediaries, then 
there are already more conduits than intermediaries. ) Further, open access removes some of the incentive to gain consumer-side profits by selling the services included in $t$. Thus, open access is not likely to increase content very much relative to closed access, and it is even possible that it could reduce it. (iii) Network neutrality removes the possibility of restricting content to trade off consumer-side profits for content-side profits. Thus it always provides weakly more content than closed or open access, and in this scenario it may provide a lot more because without it there are large incentives to restrict content to acquire profits from the content side of the market.

This scenario has similarities to the rise of Microsoft. For years antitrust policy focused on IBM's supposed control of computer infrastructure, and no one expected that the real market power lay in the operating system. Open access is not really the main issue for competition policy in this scenario; the main issue is the intrinsic uncompetitiveness of the intermediary industry and the stronger effect of full network neutrality.

Overall Welfare Effect. Translating our findings on the number of content firms into economic welfare results depends critically on two factors. First, if DSP indicates decreasing net total surplus due to fixed costs, in the sense of Mankiw and Whinston (1986), then less content actually increases economic welfare. We think it is more likely that DSP indicates increasing total surplus but decreasing surplus appropriable by the intermediary, in which case reduced content reduces economic welfare. Second, the number of intermediaries and number of conduits also affects welfare, both due to the fixed costs of intermediaries and conduits and because of the value for product differentiation implicit in the logit function. The strength of this effect becomes more important as $\sigma$, the variance of preferences, rises. The net effect on total welfare is thus very sensitive to all of these assumptions. We suggest that the greater part of the regulatory policy surveyed above is predicated on 
the idea that larger numbers of conduits, intermediaries, and content firms are all associated with higher welfare. But we caution that this does not lead to any easy comparisons. Network neutrality, for example, could easily increase the amount of content and decrease the number of intermediaries relative to closed access, making for difficult welfare comparisons.

\section{Conclusion}

\subsection{Extensions}

The model we have presented is flexible to a variety of situations that may be important as broadband Internet (and wireless) evolves. The following are some possible extensions and suggestions for future research.

The Online Population. Throughout the model, the number of consumers, $M$, is assumed constant. In places where broadband is saturated, this assumption is justified, but in growing demand areas, the growing $M$ strengthens the demand effect: more content would bring more people online. The probable result would be greater content competition in equilibrium (under either closed or open access) and less reason for network neutrality regulation in growing markets.

Geographical Footprints. In this model, the conduits and intermediaries are assumed to cover the same geographic area, so that both types of firms compete for the same number of households, $M$. The major intermediaries actually have a larger geographic footprint than the conduits. A full analysis would include a bargaining decision as independent conduits formed alliances with national or international intermediaries.

Partial Vertical Integration: Conduits Own One Intermediary. It is likely that one of the intermediaries on each open access conduit would actually be owned by the conduit. This has two implications for the model. First, assuming conduit-owned intermediaries continued to be 
proprietary, the mix-and-match assumption would be partially violated. It would not be possible to access, for example, Comcast's intermediary over Verizon's broadband conduit. If each of the conduits' proprietary intermediaries were equally "good," this would cause no change in the model. But if one conduit had an especially attractive intermediary, it would skew consumers' conduit subscription choices. Second, the conduit-owned intermediary would have a greater incentive to provide content than the non-conduit-owned intermediaries, because more content would bring in more subscribers to the conduit as well as the intermediary. The conduit would also have an incentive to discriminate in favor of its proprietary intermediary in terms of quality of transmission (Economides 1998).

Multi-homing. Recent papers have examined the situation where network consumers multi-home by using more than one platform (Caillaud and Jullien 2003, Doganoglu and Wright 2006). They find that multihoming generally increases the competitiveness of the industry. In our setting, multi-homing would involve consumers using more than one intermediary to access content. This would increase competition in the content market, lowering content firm profits and reducing the incentive to restrict content in the first place. If multi-homing were sufficiently widespread, it could produce a network-neutrality-like outcome on its own. However, we believe that the example of Google's large market share in the search-engine market, even though there are other search engines that are free and accessible using the same web browser, suggests that multi-homing exerts limited influence in this market.

\subsection{Conclusion}

The policy debate has proceeded under the assumption that conduits have very high fixed costs and are not very competitive with one another, while intermediaries have very low fixed costs and are very competitive with one another. The model developed in this paper has shown that 
under these assumptions, open access produces much greater competition in the content industry, though probably with the tradeoff that there are fewer conduits built. If those assumptions do not hold, then open access has much less positive effects on content competition, and can even lead to a less competitive content industry. When the intermediary industry is less competitive, open access and network neutrality have different outcomes.

We have emphasized that openness of the conduit to intermediaries is not equivalent to openness of intermediaries to content. The first is a regulatory decision, the second has so far been left to the market. We saw in the model that consolidation in the intermediary industry can lead to less content availability regardless of whether there is open or closed access. If the primary policy goal is to preserve access to content, it may be more effective to consider a network neutrality requirement that includes the intermediaries themselves. 


\section{References}

Anderson K, K Fjell, and ØForos (2004) Are Interactive TV-Pioneers and Surfers Different Breeds? Broadband Demand and Asymmetric Cross-Price Effects. Review of Industrial Organization 25: 295-316.

Anderson S, A de Palma, and J-F Thisse (1992) Discrete Choice Theory of Product Differentiation MIT Press, Cambridge, MA.

Bernard C and B Jullien (2003) Chicken \& Egg: Competition among Intermediation Service Providers. RAND Journal of Economics 34: 309328.

Chipty T (2001) Vertical Integration, Market Foreclosure, and Consumer Welfare in the Cable Television Industry. American Economic Review 91: 428-453.

Church J and N Gandal (1992) Network Effects, Software Provision, and Standardization. Journal of Industrial Economics 40: 85-103.

Church J and N Gandal (2000) Systems Competition, Vertical Merger and Foreclosure. Journal of Economics and Management Strategy 9: 2551.

Coffman K and A Odlyzko (2002) Internet Growth: Is there a 'Moore's Law' for Data Traffic? In: Abello J, P Pardalos, and M Resende (eds) Handbook of Massive Data Sets Kluwer, 47-93.

Doganoglu T and J Wright (2006) Multihoming and Compatibility. International Journal of Industrial Organization 24: 45-67. 
Economides N (1998) The Incentive for Non-Price Discrimination by an Input Monopolist. International Journal of Industrial Organization 16: $271-284$.

Evans D (2003) The Antitrust Economics of Multi-Sided Platform Markets. Yale Journal on Regulation 20: 325-381.

FCC (1999) Broadband today Cable Services Bureau, Washington DC.

FCC (2002) In the matter of inquiry concerning high-speed access to the internet over cable and other facilities. FCC No. 02-77, Washington DC.

Faulhaber G and C Hogendorn (2000) The Market Structure of Broadband Telecommunications. Journal of Industrial Economics 48: 305329.

Ferreira R and J-F Thisse (1996) Horizontal and Vertical Differentiation: The Launhardt Model. International Journal of Industrial Organization 14: $485-506$.

Gehrig T (1998) Competing Markets. European Economic Review 42: $277-310$.

Greenstein S (2000) The Evolving Structure of Commercial Internet Markets. In: Brynjolfsson E and B Kahin (eds) Understanding the Digital Economy: Data, Tools, and Research MIT Press, Cambridge, MA, $151-184$.

Greenstein S (forthcoming) Innovation and the Evolution of Market Structure for Internet Access in the United States. In: W Aspray and P 
Ceruzzi (eds) The Commercialization of the Internet and its Impact on American Business MIT Press, Cambridge, MA.

Hahn R and S Wallsten (2006) The Economics of Net Neutrality, The Economists' Voice 3.

Hausman J (2002) Internet-Related Services: The Results of Asymmetric Regulation. In: Crandall R and J Alleman (eds) Broadband Brookings Institution Press, Washington, DC, 129-156.

Hazlett T and G Bittlingmayer (2003) The Political Economy of Cable 'Open Access.' Stanford Technology Law Review 4.

Hogendorn C (2005) Regulating Vertical Integration in Broadband: Open Access versus Common Carriage. Review of Network Economics 4: 1932.

Lemley M and L Lessig (2001) The End of End-to-End: Preserving the Architecture of the Internet in the Broadband Era. UCLA Law Review 48: 925-972.

Mankiw N and M Whinston (1986) Free Entry and Social Inefficiency. RAND Journal of Economics 17: 48-58.

National Research Council (NRC) (2002) Broadband: Bringing Home the Bits National Academy Press, Washington DC.

Rhee, B-D (1996) Consumer Heterogeneity and Strategic Quality Decisions. Management Science 42: 157-172. 
Rochet, J-C and J Tirole (2006) Two-Sided Markets: A Progress Report. The RAND Journal of Economics.

Rubinfeld D and H Singer (2001) Vertical Foreclosure in Broadband Access. Journal of Industrial Economics 49: 299-318.

Savage S and M Worth (2005) Price, Programming and Potential Competition in US Cable Television Markets. Journal of Regulatory Economics 27: 25-46.

Shaked A and J Sutton (1982) Relaxing Price Competition through Product Differentiation. Review of Economic Studies 49: 3-13.

van Schewick B (2007) Towards an Economic Framework for Network Neutrality Regulation. Journal on Telecommunications and High Technology Law 5.

Wu, Tim (2003) Network Neutrality, Broadband Discrimination. Journal on Telecommunications and High Technology Law 2. 


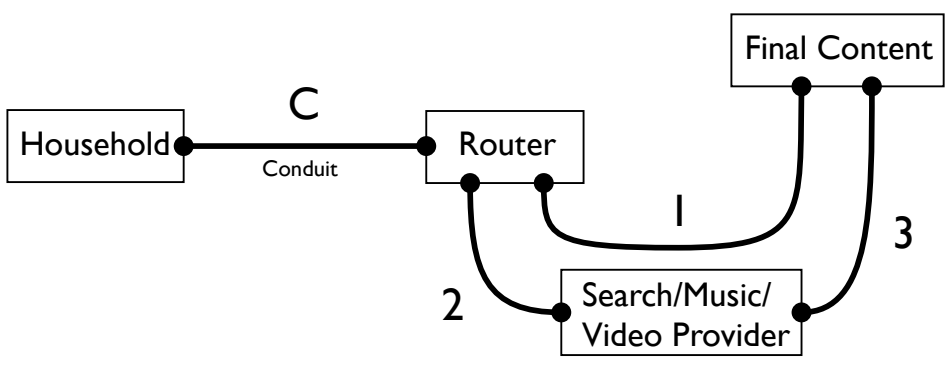

Figure 1 